Figure 3

Self-reported membership of environmental organizations

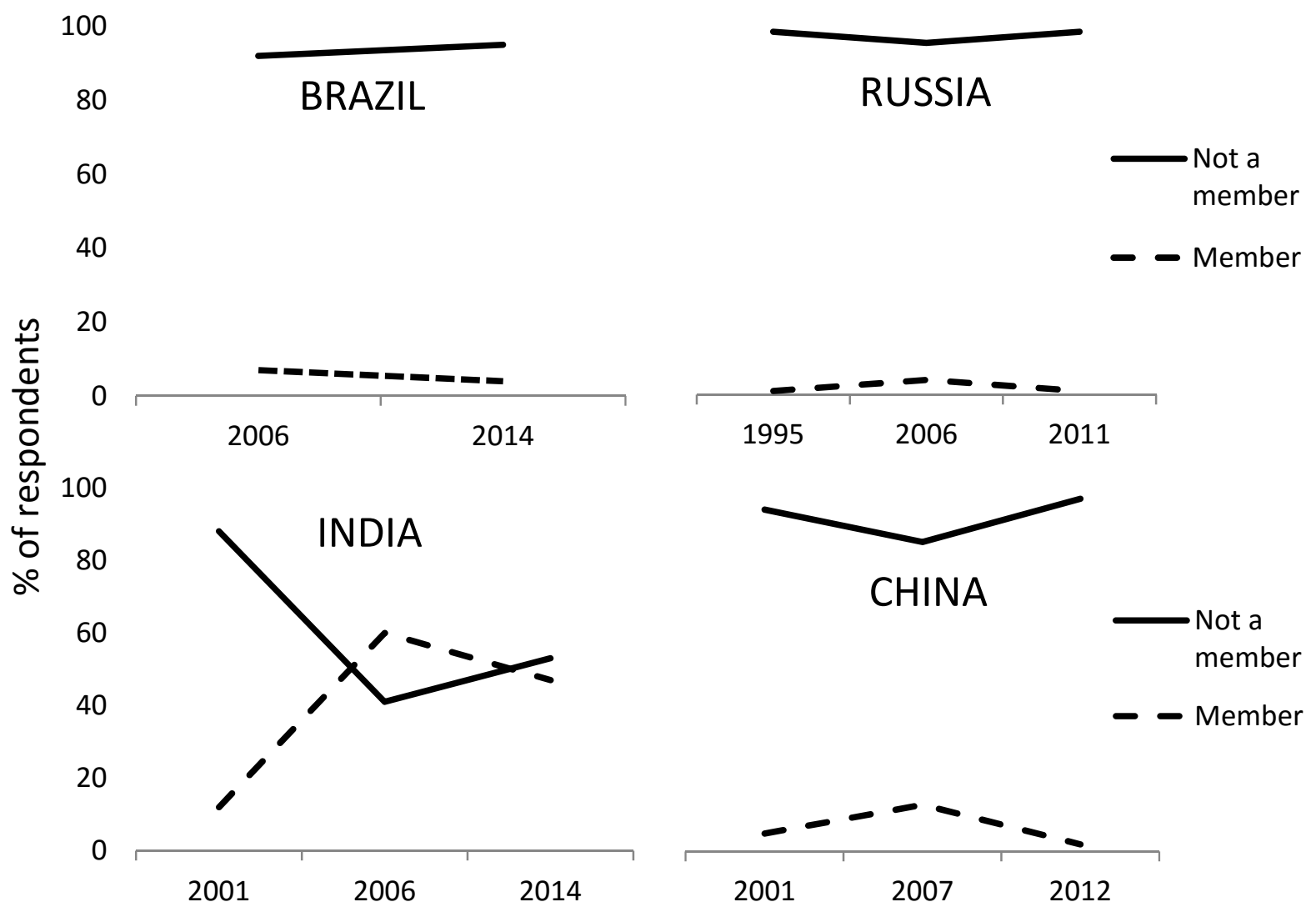

Source: World Values Survey (www.worldvaluessurvey.org) - Wave 4 (1999 - 2004), Wave 5 (2005 2009), Wave 6 (2010 - 2014). 


\title{
Public Support for Environmental Organizations in BRIC Countries
}

\author{
Alex Y. Lo \\ University of Hong Kong, Hong Kong
}

Email address: alexloyh@hku.hk

Citation:

Lo, A.Y. (in press) Public Support for Environmental Organizations in BRIC Countries, The Geographical Journal. DOI: http://dx.doi.org/10.1111/geoj.12163

Publisher version available from authors: alexloyh@hku.hk 


\begin{abstract}
The four BRIC countries (Brazil, Russia, India, and China) have recently come under environmental spotlight. These fast-growing and influential economies could become a new site for environmental activism to prosper. As the public have gained wealth for meeting their material needs, they tend to give stronger support for protecting the environment and participate in environmental movements. However, there are initial signs of declining confidence and membership in environmental organizations in BRIC countries. Caution is required when celebrating the emergence of environmental citizenship in the developing world. Further efforts are needed to address the interplay of improving economic conditions and enduring sociopolitical impediments in mobilizing public engagement in collective environmental action.
\end{abstract}

Keywords: environmental action; development; civil society; BRIC countries 


\section{Introduction}

Inglehart (1990) has argued that national prosperity enabled advanced industrial societies to switch from materialist values that emphasize economic and security needs to post-materialist ones, such as fighting for the non-human world at the expense of short-term economic benefits. Post-materialism implies that wealthier societies are more concerned about environmental sustainability, especially global environmental problems, such as climate change (Inglehart, 1995). Broadly consistent with the view of Inglehart (1990), Franzen and Meyer (2010) argue that people in rich countries are more likely to take action for protecting the environment. They claim to have found empirical evidence for what they call a 'prosperity' hypothesis, which postulates a positive relationship between a country's wealth and the level of environmental concern of its citizens (Franzen and Meyer 2010, p. 221).

Dunlap and York (2008) call into question this 'conventional wisdom' by showing that environmental concern is not limited to countries in the Global North and has reached a sufficiently high level in the South. Evidence does indicate a great leap of environmental concern across Southern countries. Kim and Wolinsky-Nahmias (2014), for example, find that citizens of developing countries are more likely than developed countries to give priority to addressing climate change. Middle-income countries are particularly concerned about the risks of environmental change arising from human interventions, such as air pollution and genetic modification of crops (Lo, forthcoming). Findings of other cross-national studies have also demonstrated that citizens of lower income countries expressed higher levels of willingness to make economic sacrifices for the environment (Fairbrother, 2013, Gelissen, 2007, Knight and 
Messer, 2012). These observations directly challenge the post-materialist assumption by suggesting that environmental activism and public support for environmental protection are no longer limited to the wealthier sectors of the world and have become a global phenomenon (Dunlap and York, 2008, Adeola, 1998).

Informed public support is crucial for enhancing the legitimacy of environmental actions and campaigns championed by civil organizations. Fast-growing economies in the South could become a new site for environmental activism to prosper, to the extent that economic conditions, people's well-being and their environmental awareness are improving. The usual expectation, however, has met with initial signs of declining environmental group membership. In this Commentary, I provide some evidence and call for further efforts on exploring the relationship between environmental activism and development in emerging economies, notably BRIC countries (Brazil, Russia, India, and China).

\section{BRIC countries}

BRIC countries have come under environmental spotlight. According to the International Monetary Fund, they have more than doubled their GDP per capita since 2001 (Table 1). With a population close to 3 billion they are home to about $40 \%$ of the world's total. High-speed development, however, has contributed to the deterioration in the quality of local and global environment, perpetuating long-term environmental problems such as global climate change. The importance of the BRIC countries for the global economy and environment has given them enormous influence in international environmental negotiations, especially those on climate 
change. Strong economic performance comes with greater environmental responsibilities. So for example we saw China, the world's second largest economy, making a groundbreaking climate change deal with the US in 2014 to curb its greenhouse gas emissions. While the BRIC governments are responding (however slowly), whether the public are also prepared to act remains uncertain.

If the post-materialist assumption or the prosperity hypothesis holds, we should find citizens of BRIC countries increasingly putting the environment at a higher priority than economic growth and more actively participating in organized environmental campaigns over the last ten to fifteen years, when the BRIC economies experienced explosive growth. Environmental mobilization is primarily driven by the participatory values of post-materialism (Inglehart, 1990). This explains the fact that environmental group membership is more common in advanced industrial societies than those at a lower level of development (Dalton, 2005), partly because of the higher incomes and levels of social trust in these societies (S Ønderskov, 2008). Yet the income-driven societal transformation is a complex process, often producing mixed impacts on public environmental concern. For instance, Lo (forthcoming) has shown that although citizens of wealthier nations, such as Australia and Norway, have indicated stronger motivation to take personal action for protecting the environment than those of the lower-income ones, they tend to perceive the environmental consequences of human activities as relatively less dangerous. Environmental action and risk perception do not respond to variations in national income in the same way (Lima et al., 2005, Lo and Chow, 2015). 
As BRIC countries have made tremendous economic achievements and become a powerful player in global environmental governance, the important question we should ask is whether the BRIC societies have come to be environmentally more active. To narrow down the question relevant to the civil society: do people in BRIC countries indicate greater support to environmental movements over time? Evidence from the World Values Survey (WVS) can shed light on this.

\section{The World Values Survey}

The WVS is a global network of social scientists involving in a coordinated data collection effort across the globe (www.worldvaluessurvey.org). Every 4 to 6 years, principal investigators from each participating country conduct nationally representative surveys and interviews with citizens of their countries, using a common questionnaire. The latest round of surveys is the WVS Wave 6, which was completed during 2010-2014 and officially released in 2014. A total of 57 countries were involved and more than 85,000 individuals were interviewed. Participating countries include the BRIC, with sample sizes ranging from 1,486 (Brazil), 1,581 (India), 2,300 (China) to 2,500 (Russia).

Although the WVS mainly focuses on social, cultural and political issues, it has included in successive waves of surveys a few questions about environmental attitude and public support for environmental organizations. One of these questions requested respondents to consider the trade-off between environmental protection and economic growth and decide which one should be given higher priority (they were also allowed to provide other answers, which were recorded 
as a separate category). Two other questions probed respondent's confidence in environmental groups, with response options ranging from 'A great deal' to 'None at all', and their self-reported membership in these groups. As Dalton (2005) has pointed out, the interpretation of what constitutes an environmental group may vary across countries and all cross-national surveys inevitably encompass such variation. Nonetheless my assessment involves only a small number of major developed countries and therefore is less vulnerable to this limitation.

Public responses to the first question are presented in Figure 1. In almost all years and all of the four BRIC countries, more respondents considered environmental protection to be more important than economic growth and employment. Brazilians had little change in attitude between 2006 and 2014. Both Russia and China witnessed a small increase in the proportion of respondents assigning higher priority to environmental protection during the past ten years. Nevertheless, at the same time more Russian and Chinese citizens saw economic growth a more important imperative in $2011 / 2012$ than $2006 / 2007$, suggesting a parallel marginal increase in support for both positions in recent years. India is an exception; the preference for economic growth exceeded preference for environmental protection in 2014. Only 1\% more Indians accepted the environmental position. But the evidence from India has to be interpreted with care, because as much as $38 \%$ of respondents elected to provide other answers or did not reveal their opinions, whereas only $14 \%$ did so in 2014 . Overall, public attitude toward costly efforts on environmental protection in BRIC countries has elevated, albeit by a modest degree.

Changes in confidence in environmental organizations are shown in Figure 2. Fewer respondents from Brazil and Russia expressed confidence than in preceding years. The tendency 
in China is less clear, where the decline in confidence was observed in 2007 but not in 2012. In India, confident respondents increased by a fairly large margin between 2001 and 2014, while the proportion of those returning a negative response fluctuated during this period. Again, care is required for interpreting the data collected from India because the number of 'No answer' and 'Don't know' responses dropped from 37\% in 2006 to 1\% in 2014. To summarize, there is no clear evidence showing a significant improvement in public confidence in environmental organizations, except in India. Loss of confidence is looming within part of the BRIC societies.

A more consistent pattern of variations was found in environmental group membership across BRIC countries (Figure 3). Less than $5 \%$ of respondents in Brazil, Russia, and China identified themselves a member of an environmental group. Fewer respondents declared group membership in WVS Wave 6 (2010 - 2014), although the number of members had moved up in Russia and China in Wave 5 (2005-2009). India saw a marked increase in the proportion of respondents registering group membership between 2001 and 2006, but the tendency reversed in 2014, resulting in a nearly equal split between members (47\%) and non-members (53\%). The latest WVS results indicate that reported membership in environmental organizations in BRIC countries has waned in the past few years.

\section{Conclusions}

The debate remains unresolved as to whether or not environmental activism is a function of economic development. Conflicting evidences have been found in different and even the same sources of data (e.g. Franzen and Meyer, 2010 and Lo, forthcoming). There is no doubt that 
citizens of BRIC countries have become more concerned about the environment as these fastgrowing economies have accumulated a certain level of wealth and more people are committed to post-materialist goals. However, the transformation of environmental attitude is a slow process and, in some cases, accompanied by a parallel change in preference for economic growth in favour of environmental protection, i.e. polarization of opinions.

An alarming observation is that confidence and participation in environmental organizations appear to have come to a bottleneck point. There may be a discrepancy between activism and growth; that is, progress in domestic environmental mobilization in BRIC countries is lagging behind their strong momentum in national development. Dalton (2005, p. 455) has offered a reason for the discrepancy observed:

[E]nvironmental concerns in less developed nations will have difficulty mobilising broad public involvement because they often lack the proper infrastructure, are frequently occurring in undemocratic circumstances and green NGOs will have difficulty using appeals based on ecologism to recruit members.

The second point is related to institutional barriers and particularly relevant to developing countries strongly influenced by non-liberal political traditions. The Russian and Chinese economies expanded at a much faster rate than Brazil and India (see Table 1), but survey data obtained from Russia and China demonstrate clearer and more consistent changes in confidence and group membership in environmental organizations than the latter two (see Figures 2 and 3 ). One key difference between the two groups is that the ruling regimes of Russia and China currently tend to be authoritarian. In both countries, civil society actors without political blessing 
have encountered different forms of political restriction and marginalization by the state. The limited political access and influence have compromised the capacity of environmental groups to transmit the public's voices to policy-making process. This situation is not uncommon in the postsocialist world. In Kazakhstan, for example, environmental activism is rising and has drawn the government's attention, but it is difficult to identify the direct impact of environmental groups and civic organizations on government decisions (Soltys and Orynbassarova, 2013). To the extent in which civic participation and political campaigns led by environmentalists are not clearly consequential, environmentally conscious citizens may turn their efforts to lifestyle adjustments as an alternative form of contribution.

This possible explanation requires further evidence on the intricate linkages between environmental activism and economic growth. In particular we need to address the interplay of improving economic conditions and enduring socio-political impediments in mobilizing public engagement in collective environmental action. Looking into the future, environmental mobilization in the upper end of the developing world will definitely find more resources than 20 years ago to support their activities, but the socio-political context of some non-liberal democracies is likely to continue to pose challenge to conventional forms of mobilization as we have seen in advanced industrial societies.

\section{References}

Adeola, F O 1998 Cross-national environmentalism differentials: Empirical evidence from core and noncore nations. Society \& Natural Resources 11 339-64.

Dalton, R J 2005 The Greening of the Globe? Cross-national Levels of Environmental Group Membership. Environmental Politics 14 441-59. 
Dunlap, R E \& York, R 2008 The globalization of environmental concern and the limits of the postmaterialist values explanation: Evidence from four multinational surveys. Sociological Quarterly 49 529-63.

Fairbrother, M 2013 Rich People, Poor People, and Environmental Concern: Evidence across Nations and Time. European Sociological Review 29 910-22.

Franzen, A \& Meyer, R 2010 Environmental Attitudes in Cross-National Perspective: A Multilevel Analysis of the ISSP 1993 and 2000. European Sociological Review 26 219-34.

Gelissen, J 2007 Explaining Popular Support for Environmental Protection: A Multilevel Analysis of 50 Nations. Environment and Behavior 39 392-415.

Inglehart, R 1990 Culture Shift in Advanced Industrial Society Princeton University Press, Princeton,NJ.

Inglehart, R 1995 Public support for environmental protection: Objective problems and subjective values in 43 societies. PS: Political science and politics 28 57-72.

Kim, S Y \& Wolinsky-Nahmias, Y 2014 Cross-National Public Opinion on Climate Change: The Effects of Affluence and Vulnerability. Global Environmental Politics 14 79-106.

Knight, K W \& Messer, B L 2012 Environmental Concern in Cross-National Perspective: The Effects of Affluence, Environmental Degradation, and World Society. Social Science Quarterly 93 521-37.

Lima, M L, Barnett, J \& Vala, J 2005 Risk Perception and Technological Development at a Societal Level. Risk Analysis 25 1229-39.

Lo, A Y forthcoming National Income and Environmental Concern: Observations from 35 countries. Public Understanding of Science.

Lo, A Y \& Chow, A Y 2015 The relationship between climate change concern and national wealth. Climatic Change.

SØnderskov, K M 2008 Environmental group membership, collective action and generalised trust. Environmental Politics 17 78-94.

Soltys, D \& Orynbassarova, D 2013 Delivering Environmental Education in Kazakhstan Through Civic Action: Second-Wave Values and Governmental Responses. Environmental Values 22 101-22. 
Table 1 GDP per capita and population of BRIC countries

\begin{tabular}{lrrrrr} 
& \multicolumn{2}{c}{ GDP per capita (current US prices) } & \multicolumn{2}{c}{ Population (millions) } \\
& \multicolumn{1}{c}{2001} & \multicolumn{1}{c}{2013} & Change (\%) & \multicolumn{1}{c}{2001} & \multicolumn{1}{c}{2013} \\
\hline Brazil & 3,151 & 11,173 & 255 & 176 & 201 \\
Russia & 2,111 & 14,591 & 591 & 145 & 143 \\
India & 471 & 1,509 & 220 & 1,048 & 1,243 \\
China & 1,032 & 6,959 & 574 & 1,276 & 1,361 \\
\hline
\end{tabular}

Source: International Monetary Fund's World Economic Outlook 2014 
Figure 1 Relative importance of environmental protection and economic growth in BRIC countries

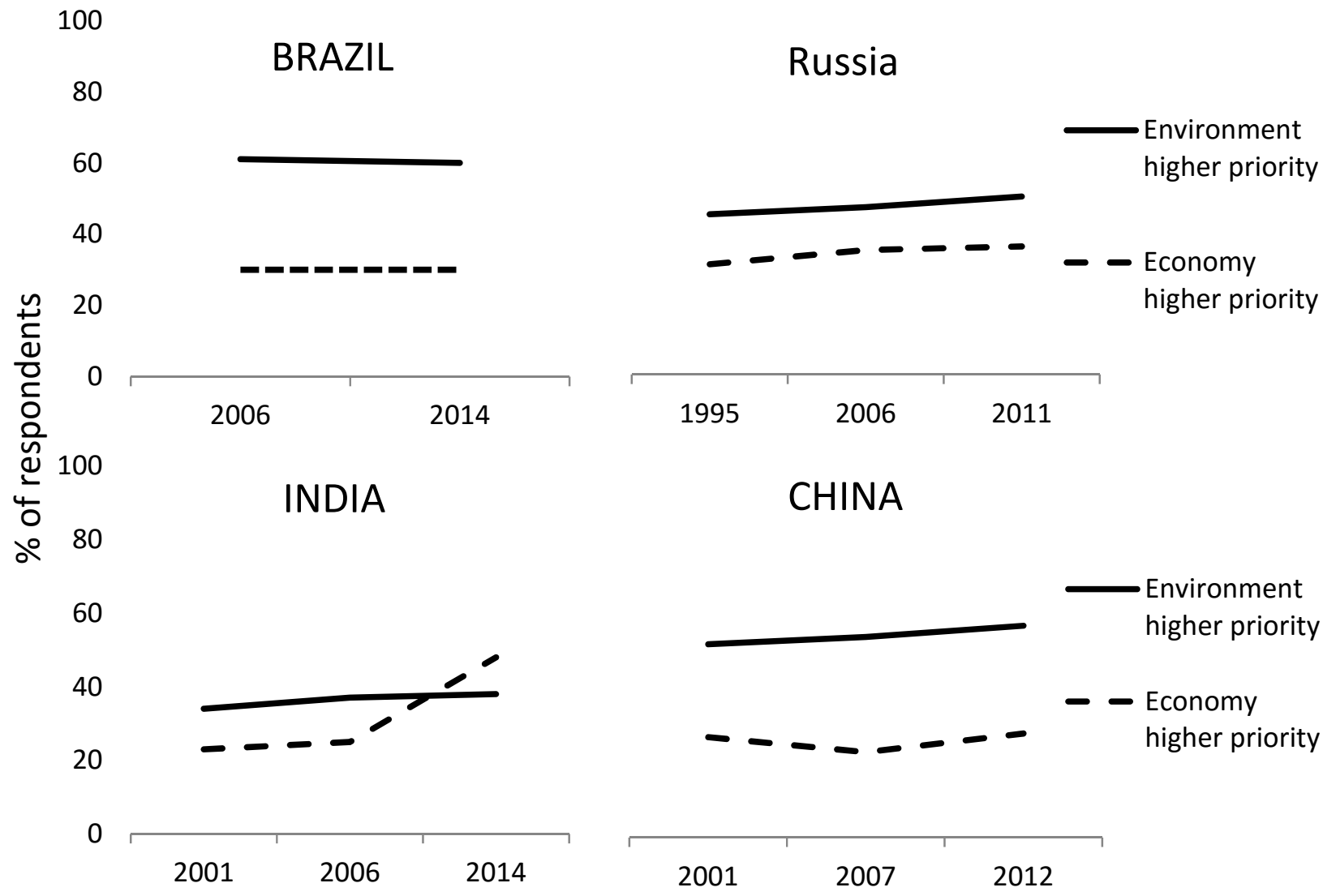

Source: World Values Survey (www.worldvaluessurvey.org) - Wave 4 (1999 - 2004), Wave 5 (2005 2009), Wave 6 (2010 - 2014).

Notes:

1. Respondents were requested to indicate which of the following two statements comes closer to their own point of view: 'Protecting the environment should be given priority, even if it causes slower economic growth and some loss of jobs' (Environment higher priority), and 'Economic growth and creating jobs should be the top priority, even if the environment suffers to some extent' (Economy higher priority).

2. Russia was not included in WVS Wave 4, so that results of Wave $3(1995-1999)$ were used as an alternative. Brazil was not included in the WVS Wave 3 and Wave 4.

3. The 'No answer', 'Other answer', and 'Don't know' options are omitted from the graphs. 


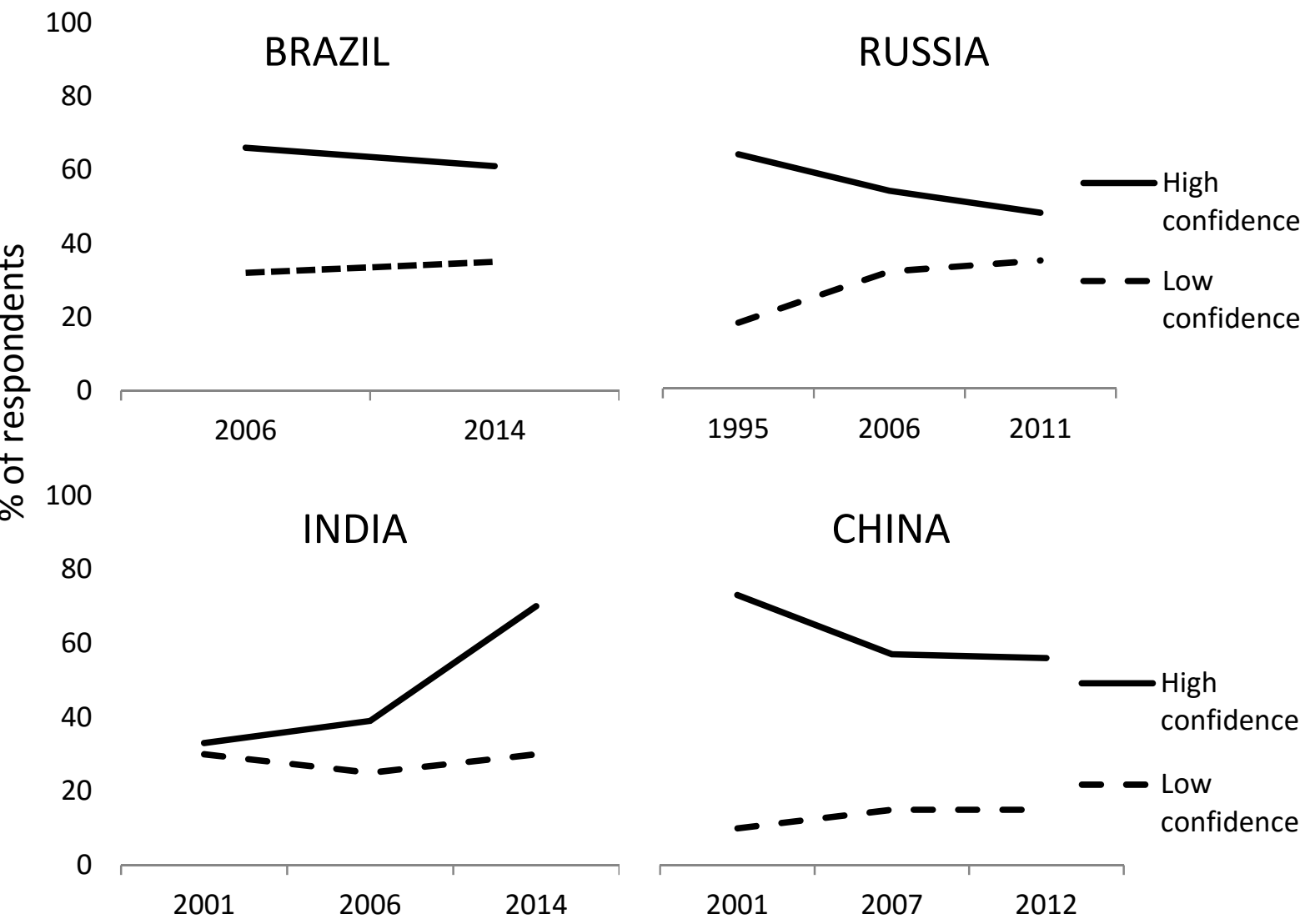

Source: World Values Survey (www.worldvaluessurvey.org) - Wave 4 (1999 - 2004), Wave 5 (2005 2009), Wave 6 (2010 - 2014).

Notes:

1. 'High confidence' combines two positive response options, i.e. 'A great deal' or 'Quite a lot', whereas 'Low confidence' includes 'Not very much' or 'None at all'.

2. Russia was not included in Wave 4, so that results of Wave $3(1995-1999)$ were used as an alternative. Brazil was not included in the WVS Wave 3 and Wave 4.

3. The 'No answer' and 'Don't know' options are omitted from the graphs. 


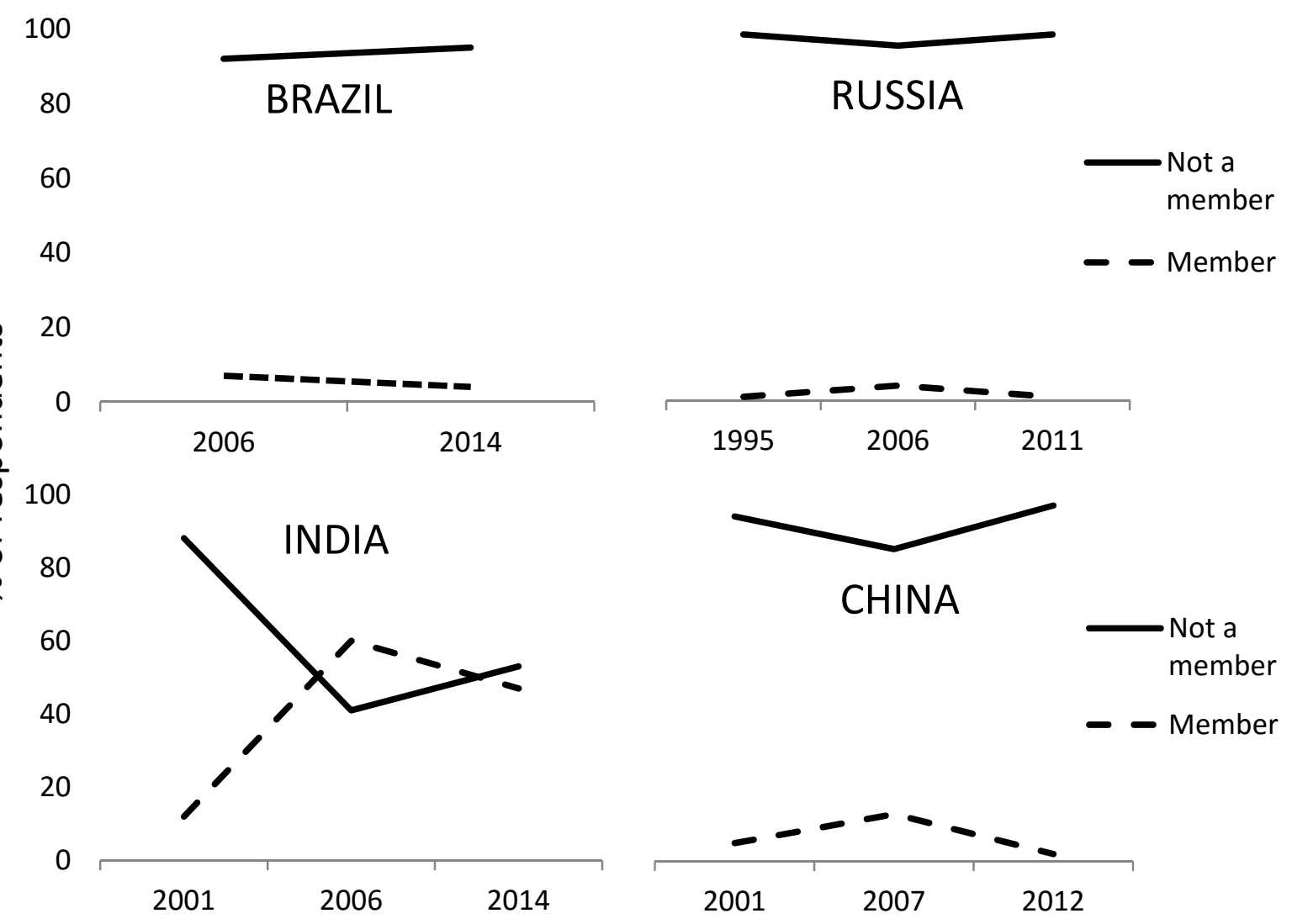

Source: World Values Survey (www.worldvaluessurvey.org) - Wave 4 (1999 - 2004), Wave 5 (2005 2009), Wave 6 (2010 - 2014).

Notes:

1. 'Member' includes 'Inactive member' and 'Active member'.

2. Russia was not included in Wave 4 , so that results of Wave 3 (1995 - 1999) were used as an alternative. Brazil was not included in the WVS Wave 3 and Wave 4. 
